\title{
Review
}

Dig Surg 2003;20:3-9

DOI: $10.1159 / 000068850$

\section{Incisional Hernias}

\author{
I. Related Risk Factors
}

\section{Elie Yahchouchy-Chouillard Tamer Aura Olivier Picone J ean-Charles Etienne Abe Fingerhut}

Digestive Surgery Department, Centre Hospitalier Intercommunal, Poissy, France

\section{Key Words}

Hernia • Incisional suture · Risk, hernia · Wound

infection, hernia . Dehiscence

\begin{abstract}
Incisional hernias represent one of the most frequent complications of abdominal surgery. The incidence is probably underestimated. The pathogenesis is complex and not fully understood, implying patient-related factors (i.e., collagen biochemistry, obesity, age) as well as technical factors, including, among others, wound infection, suture material, and types of incisions and closures. In this paper, the first of two, the authors review the literature emphasizing the current knowledge concerning the pathogenesis of incisional hernias. The second article is focused on the treatment.
\end{abstract}

\section{Introduction}

Incisional hernias (IH) are one of the most common complications of abdominal surgery, with an overall estimated incidence ranging from 2 to $11 \%$ after abdominal operations [1-8]. Among these, $80-95 \%$ develop within 6 months [9] to 3 years after initial surgery $[4,10,11]$. How- ever, the true incidence is probably underestimated. Eight to $29 \%$ of the IH are asymptomatic and, therefore, remain unaccounted for, if the patient is not examined physically [12-14]. Wound infection, obesity, and suture closure technique are thought to be the most important risk factors for the development of IH [15-17]. The financial cost of the repair of an IH is approximately USD 6,000, without considering the loss of productivity [18]. Hence, one can imagine the important economic impact of reducing the incidence of IH in this era of retraction of resources.

The purpose of this article, the first of two, is to review the current knowledge of factors predisposing to $\mathrm{IH}$ and to update the modalities of their prevention. The second article will deal with the therapeutic options for the management of $\mathrm{IH}$.

\section{Patient-Related Factors}

Mudge and Hughes [4], among others [19], showed that more than $50 \%$ of the IH occurred during the 1 st year postoperatively. Almost $80 \%$ of the IH occurred within 3 years in the same series [4, 19]. Another study [20] reported that $52 \%$ of the $\mathrm{IH}$ appeared within 6 months postoperatively, $68 \%$ within 1 year postoperatively, and $79 \%$ within 2 years postoperatively. It seems more and more plausible that a malunion occurs between the edges

\begin{tabular}{ll}
\hline KARGER & ( ) 2003 S. Karger AG, Basel \\
0253-4886/03/0201-0003\$19.50/0 \\
$\begin{array}{l}\text { Fax +4161306 12 34 } \\
\begin{array}{l}\text { E-Mail karger@karger.ch } \\
\text { www.karger.com }\end{array}\end{array}$ & $\begin{array}{l}\text { Accessible online at: } \\
\text { www.karger.com/dsu }\end{array}$
\end{tabular}

Abe Fingerhut, MD

Centre Hospitalier Intercommunal

10, rue de Champ-Gaillard

F-78303 Poissy Cedex (France)

Tel. +33 1392751 65, Fax +331392744 02, E-Mail AbeFinger@aol.com 
Table 1. Patient-related risk factors for IH

\begin{tabular}{ll}
\hline Major factors & Minor factors \\
\hline Chronic lung disease & Age \\
Obesity & Male gender \\
Steroids & Postoperative ventilation \\
Type II diabetes mellitus & Renal failure \\
Malnutrition & Connective tissue disorders \\
Jaundice & Malignancy \\
Radiotherapy & Transfusion \\
Chemotherapy & Anemia \\
Oral anticoagulants & \\
\hline
\end{tabular}

of the incised aponeurosis soon after operation and that the weak fibrous tissue forming that malunion insidiously stretches, until the IH becomes clinically detectable [13]. Hence, as many as $94 \%$ of the IH may occur within 30 days after surgery [13].

Recurrent IH, however, do appear earlier. In one study [21], $82 \%$ of the recurrences became manifest within the 1st year. Langer and Christiansen [6], among others [12], found that most recurrences appeared within the first 3 years and that most of them recurred within the 1st year. The most common risk factor of the recurred IH seems to be the size of the primary IH [12]. Other factors incriminated are obesity, diabetes mellitus, lower midline incision, and wound infection [12].

Patient-related factors that increase the risk of developing IH include mainly obesity, chronic lung disease, type II diabetes mellitus, age, malnutrition, renal failure, malignancy, and steroid treatment (table 1) [22-34].

Blood transfusion may predispose to wound failure and IH [35]. This parameter was seldom studied in the literature. Malignant disease is frequently associated with an increased incidence of IH. To our knowledge, this dogma is more theoretical than practical, since many investigators showed no statistically significant result [13]. However, cytotoxic agents, malnutrition, and radiotherapy are thought to be important contributing factors to wound disruption or IH [12, 24, 36].

Oral anticoagulants, by elevating the incidence of postoperative hematoma and wound infection, seem to be a risk factor for $\mathrm{IH}[25,37]$.

Jaundice is considered by many to be a risk factor for dehiscence and IH [38]. Experimental evidence suggests that obstructive jaundice decreases the strength of abdominal wound healing and delays fibroplasia and angiogenesis [39].

\section{Wound-Related Factors}

\section{Biochemical Pathogenesis}

Despite numerous predisposing factors, including anatomical features (persistence of the peritoneal-vaginal conduit, high insertion point of the transverse arch) and those associated with other diseases (obesity, chronic obstructive pulmonary disease, constipation), the underlying cause of the development of hernias, either primary or incisional, seems to be of a biologic nature. Research aimed at evaluating the role played by biological factors has centered on possible alterations in connective tissue metabolism. An abnormal collagen metabolism has been ascribed an important role in the genesis of $\mathrm{IH}$ and the high recurrence rates after surgical hernia repair [40]. This idea is also supported by the fact that diseases such as Marfan and Ehlers-Danlos syndromes, cutis laxa, osteogenesis imperfecta, and congenital hip dislocation have been associated with hernial processes. Experimentally studied tissue specimens from such patients with hernias have included the rectus sheath, cremaster, hernial sac, and even skin tissue [41]. The expression patterns of certain types of collagen [42] and certain enzyme dysfunctions [43] have also been the subject of several studies. Metalloproteinases (MMP) represent a group of enzymes which degrade and contribute to the turnover of the extracellular matrix, acting on certain types of collagen and elastin. The ratio collagen I/III is decreased in patients with hernias, either indirectly or directly [40]. Furthermore, in these patients the expression of MMP-1 and MMP-13 is decreased. The decreased ratio collagen I/III is due to a relative increase of collagen type III which is known to be characterized by thin fibril diameters and lowered mechanical strength. The altered collagen ratio might be the result of the decreased activity of MMP-1, whereas the absent MMP-13 expression does not seem to modify the scar formation according to some investigators [40].

A balance between extracellular matrix synthesis and degradation is important for tissue integrity, because remodeling occurs relentlessly. Structural changes or defects in molecules may alter the tissue architecture, resulting in an impairment of the proper assembly of the components and modifying the mechanical properties of the tissue. The pathological hernia process seems then to be related to MMP secretion. For example, fibroblasts from the abdominal wall of young patients with direct hernias show increased active MMP-2 expression [44]. The MMP-2 expression is enhanced in processes such as genitourinary prolapse [45] and aortic aneurysm [46]. Fur- 
ther, it has been reported that patients with this latter pathology have an increased incidence of hernias [47, 48]. This enzyme may be intimately involved in the extracellular matrix degradative process. The persistence of this alteration in the fibroblast cultures appears to indicate a genetic defect or perhaps later transformation as the underlying cause of this pathology, ruling out environmental factors as the main cause.

\section{Peritoneal Closure}

The prevention of adherence of small bowel to the abdominal wall is a major argument for proponents of peritoneal closure [18]. However, peritoneal closure causes more adhesions in animals. Moreover, in humans, the incidence of $\mathrm{IH}$ has not been reduced by peritoneal closure [49]. Since the holding strengths of sutures placed in the posterior rectus sheath - intimately attached to the peritoneum - alone or in the anterior rectus sheath alone are identical [50], the holding strength of the closure would be reduced by $50 \%$, if the peritoneum is not closed [18]. However, only $6.1 \%$ of the patients have an IH after breast reconstruction with a rectus abdominis myocutaneous flap with the peritoneum as the only barrier to herniation in the lower abdomen [18].

\section{Type of Incision}

The choice of an incision in abdominal surgery depends on the surgeon's preference, but is also determined by the adequacy of exposure and access provided. It should take into account the anticipated pathology and the contemplated operative procedure, or, on the other hand, be sufficiently versatile in the emergency situation, in order to meet the demands. Patient obesity and previous incisions may also intervene in the decision.

In traditional (open) surgery, the midline incision is the simplest, provides adequate exposure to practically all four quadrants, is rapid to open and to close, and is usually bloodless. No muscle fibers need to be divided, and no nerves are injured. The midline incision is the most widely used abdominal incision [51]. However, IH are a major problem with the midline incision. Dehiscence has been rare, if the sutures are placed widely on each side of the incision [52]. Some surgeons place sutures in the linea alba itself rather than beyond the fusion line between the two rectus sheaths in order to avoid muscle tearing. Tera and Aberg [50] have shown that the holding strength of sutures placed widely exceeds that of sutures placed directly through the linea alba, a weak structure prone to spontaneous hernias and diastasis.
The medial paramedian incision provides adequate exposure as well, but with limited trauma to rectus muscle. No nerves are injured, the closure is reputed to be secure, but both opening and closure are more time-consuming as compared with the midline incision. Some investigators failed to establish any difference between midline incisions and medial paramedian incisions with regard to the occurrence of $\mathrm{IH}$. However, the lateral paramedian incision was shown to be better than midline or medial paramedian incisions in terms of IH risks [53]. To be effective, a paramedian incision must be lateral, not close to the midline in order to avoid ischemia of the linea alba [18]. Cahalane et al. [18] found an incidence of $0.33 \%$ of $\mathrm{IH}$ at 1 year in 1,203 lateral midline incisions from four different series.

Transverse or oblique incisions have been found to be better than the midline incisions, with less respiratory compromise, less morbidity, and, in particular, less IH $[54,55]$. Distracting forces on a vertical incision during activity during the postoperative period are said to be nearly twice as great as those on a transverse incision. Many of the trials showing that $\mathrm{IH}$ is more common after midline as opposed to transverse incisions were uncontrolled for disease process. Conditions such as emergency surgery, hemorrhage, trauma, or abdominal sepsis may have had a greater influence on the development of $\mathrm{IH}$ than the type of incision used [1]; Ellis et al. [56], in a prospective randomized trial, found no significant difference in the rates of $\mathrm{IH}$ in patients undergoing midline, paramedian, or transverse incisions. Furthermore, the strongest argument against the subcostal incision is that, unless confined exclusively to the rectus muscle, partial denervation of the abdominal wall ensues with permanent muscle weakness.

\section{Wound Infection}

Carrel [57] first described impaired wound healing secondary to infectious processes in 1924 . He created cutaneous wounds in dogs, and after several days injected turpentine into the flanks to induce abscess formation. Epithelialization and wound contraction were slowed or stopped in the infected animals. In 1974, de Haan et al. [58] found that infection decreased the bursting strength of both gastric and abdominal wounds. Although the mechanisms governing wound healing impairment by infection are still to be defined, studies on the healing of colonic anastomoses suggest that sepsis inhibits collagen synthesis at the anastomotic site [59]. A similar process affecting abdominal wounds seems likely. Riou et al. [22] identified septicemia as a risk factor for wound dehis- 
cence. Electric cautery seems to lower the threshold of bacterial infection of the laparotomy wound in rats [60]. The coagulation current caused more inflammation, necrosis, and abscesses than the scalpel at all bacterial levels. However, these results were not confirmed by clinical experience in humans [61].

Wound infection is considered by many as the most important factor contributing to the development of IH. Bucknall et al. [19] found that $48 \%$ of the patients who developed IH had wound infection during the postoperative period, the presence of a wound infection conferring a fivefold increase in the rate of IH [19].

\section{Wound Closure}

Many believe that there is no association between the method of wound closure and the incidence of IH. Moynihan [62] stated in 1920 that 'suture material should ideally: (1) achieve its purpose - be sufficient to hold parts together, close a vessel, etc.; (2) disappear as soon as its work is accomplished; (3) be free from infection, and (4) be nonirritant...'. These requisites were indeed right and still remain valid nowadays. However, Moynihan concluded: 'The only material which can be made to fulfil these conditions is catgut' [62]. However, catgut is rapidly absorbed, challenging the first item in Moynihan's definition. This illustrates the fact that the perfect suture material does not exist, since each era has had its own 'ideal' suture material. Experimental research [63] has shown that one year after laparotomy the abdominal fascia retains only $70 \%$ of its original tensile strength. Polyglactin (Vicryl) is a polymer of glycolic and lactic acids degradable over 40-60 days, and disappearing at 75 days. Vicryl resists enzymatic digestion, body secretion, as well as infection. Synthetic absorbable sutures such as polyglycolic acid and polyglactin have the advantage of disappearing in time, since they are fully absorbed after 75 days but have no strength left after 30 days. Polydioxanone-s (PDS) is only absorbed after 180 days and retains $70 \%$ of its strength after 3 weeks. It is a monofilament suture having the advantage of nylon and polypropylene with a smooth surface which slides easily through the tissues, reducing the risks of tissue necrosis and bacteria adherence $[64,65]$.

The importance of the suture length/wound length ratio has been emphasized in many studies. Using a purely mechanical approach to wound closure, Jenkins [64] in 1976 established that the correct closure of a vertical abdominal incision implies a suture length/wound length ratio $>4 / 1$.
Measurements of the xiphoid pubic distance before and after closure demonstrate that abdominal distension may lengthen the wound by $30 \%$. The continuous suture can accommodate to this increase in length of the incision by having an adequate reserve suture length in the wound. The continuous suture distributes its tension throughout the wound, limiting the forces on the tissues encircled by the sutures. This technique was experimentally proven to be associated with greater bursting pressures than the simple interrupted sutures or figure-of- 8 mattress sutures [66].

There are many prospective and retrospective studies that have compared various suture materials in abdominal wound closure. However, since the introduction of synthetic absorbable sutures, the majority of these trials have shown no difference in the overall incidence of wound complications in comparison with various nonabsorbable sutures. At least four studies [9, 67-69] compared continuous versus interrupted closure of midline incisions. All found that continuous suture closure was as effective and as safe as interrupted suture closure with the advantage of being more expeditious.

However, PDS seems to be associated with a lower rate of IH $[69,70]$. The double-stranded suture type providing nearly twice the initial tensile strength of a single strand of the same diameter may be valuable in high-risk patients (i.e., those having obesity) [70].

Finally, mechanical stress may play an important part in the development of late IH. Coughing, abdominal distension, heavy physical exercise, straining during defecation, or vomiting after operation may increase the risk of IH independently of any other associated factors [2]. In a recently published meta-analysis of the trials comparing routine to elective nasogastric decompression after elective laparotomy [71], the authors concluded that routine decompression results in a significantly increased incidence of pulmonary complications (fever, atelectasis, and pneumonia) and does not decrease the incidence of wound complications (infection and dehiscence).

The continuous double-loop closure (CDLC), using double-stranded sutures, is reputed to withstand raised intra-abdominal pressure, while apposition of the wound edges is maintained [72]. This phenomenon was expected to result in a lowering of wound pain and dehiscence. In a recent study, Niggebrügge et al. [25] compared the CDLC to the more commonly used continuous running suture in patients undergoing midline laparotomy. The CDLC technique was associated with more wound dehiscence and rupture. Although CDLC can resist high intraabdominal pressures, it seems to decrease the compliance
6

Dig Surg 2003;20:3-9
Yahchouchy-Chouillard/Aura/Picone/ Etienne/Fingerhut 
of the abdominal wall, increasing the risk of postoperative pulmonary complications and death.

\section{IH after Laparoscopic Surgery}

The incidence of IH after laparoscopic surgery is low, averaging less than $1 \%$ [73]. The diameter of the port site seems to be the major factor. Eighty-six percent of such IH develop in port sites of $10 \mathrm{~mm}$ or more [74]. There is a tenfold increase in the incidence of extraumbilical hernias, if a $12-\mathrm{mm}$ port is used. Other factors incriminated include long duration of surgery and multiple insertions, large quantities of fluid left in the peritoneal cavity, inadequate evacuation of pneumoperitoneum and unrelaxed abdominal wall at the end of the procedure, and increased abdominal pressure at the end of surgery $[75,76]$.

The closure of all port sites of $10 \mathrm{~mm}$ or more is indicated, preferentially intracorporeally under direct vision, since IH have been reported after external closure of the aponeurosis [75].

\section{Optimizing Wound Closure}

In 1998, Weiland et al. [77] reviewed the medical world literature of techniques of abdominal wound closure between 1977 and 1997 and found 25 comparative articles of which 23 were randomized. A total of 12,247 patients from nine countries were analyzed. Comparison of continuous and interrupted sutures failed to reach significance. In analyzing dehiscence, conclusions could not be drawn, since the populations compared were disproportionate, creating a type I error. The infection rate was not significantly different in all types of comparisons. The authors concluded that the choice of suture material should be based solely on the rates of IH formation. When continuous closures are chosen, nonabsorbable sutures are most appropriate. If interrupted closures are chosen, absorbable sutures should be favored. Layered closure may increase the risk of infection, hernia, and dehiscence as compared with mass closure. However, although the authors, in their meta-analysis, used the Stouffer method based on the standard deviation $\mathrm{Z}$ score, with a special attention to type II errors, the drawn conclusions are difficult to generalize.

In 2000, Hodgson et al. [78] reviewed all randomized clinical trials conducted in adults and published in English between 1966 and 1998, excluding those comparing two sutures of the same category and with the same tech- nique. Strict methodological barriers for inclusion were set, including mainly the Jadad Quality Score [79]. IH were $32 \%$ less frequent with nonabsorbable sutures as compared with absorbable sutures. Although the infection rates were not significantly different, nonabsorbable sutures were associated with an increased rate of cutaneous sinuses and wound pain. The running type of suturing was associated with significantly lower rates of $\mathrm{IH}$. The authors recommended the use of running nonabsorbable sutures as the standard modality of wound closure.

Although some discrepancies may exist with large randomized trials, meta-analysis can be a good tool to resolve clinical controversy. However, the patient populations were heterogeneous without patent data comparing patient-related factors such as obesity, steroid medication, hypoalbuminemia, age, and pulmonary diseases, among others. Additional factors of discrepancies include type of incision, antibiotic prophylaxis, the emergency type of operation, and follow-up period.

Independently of patient-related factors, the type of incision dictated by the type of the operation and the preference of the surgeon, and the type of closure, which may be layered or mass, two major factors may be controlled to some extent: the infection rate and the type of the suture material. Reducing the infection rate seems to be the key factor in reducing IH. Rigorous aseptic technique and limitation of the use of electric cautery are recommended. The most suitable suture material seems to be PDS which cumulates the short-term benefits of nonabsorbable sutures (tensile force) without accumulating their long-term inconveniences such as sinus formation and pain. The type of closure (interrupted vs. continuous) seems to be secondary, if some rules such as avoiding ischemic suturing (the figure-of- 8 type) and reducing early malunion (wide sutures) are implemented. There is no argument for recommending the preventive use of an absorbable (polyglactin) mesh placed on top of a facial closure in high-risk patients [80]. 


\section{References}

1 Santora TA, Roslyn JJ: Incisional hernia. Surg Clin North Am 1993;73:557-570.

2 Urschel JD, Scott PG, Williams HTG: Etiology of late developing hernias: The positive role of mechanical stress. Med Hypotheses 1988;25: 31-34.

3 Schoetz DJ, Coller JA, Viedenheimer MC: Closure of abdominal wounds with polydioxanone: A prospective study. Arch Surg 1988; 123:72-74.

4 Mudge M, Hughes IE: Incisional hernia: A 10year prospective study of incidence and attitudes. Br J Surg 1985;72:70-71.

5 Larson GM, Vandertoll DJ: Approaches to repair of ventral hernia and full-thickness losses of the abdominal wall. Surg Clin North Am 1984;64:335-349.

6 Langer S, Christiansen J: Long-term results after incisional hernia repair. Acta Chir Scand 1985;151:217-219.

7 Houck JP, Rypins EB, Sarfeh IJ, et al: Repair of incisional hernia. Surg Gynecol Obstet 1989; 169:397-399.

8 Deital M, Alhindawi R, Yamen M, et al: Dexon plus versus Maxon fascial closure in morbid obesity: A prospective randomized comparison. Can J Surg 1990;33:302-304.

9 Richards PC, Balch CM, Aldrete JS: Abdominal wound closure: A randomized prospective study of 571 patients comparing continuous versus interrupted suture techniques. Ann Surg 1983; 197:238-243.

10 Ellis H, Gajraj H, George CD: Incisional hernias: When do they occur? Br J Surg 1983;70: 290-291.

11 Read RC, Yonder G: Recent trends in the management of incisional herniation. Arch Surg 1989; 124:485-488.

12 Hesselink VJ, Luijendijk RW, de Wilt JHW, et al: An evaluation of risk factors in incisional hernia recurrence. Surg Gynecol Obstet 1993; 176:228-234.

13 Pollock AV, Evans M: Early prediction of late incisional hernia. Br J Surg 1989;76:953-954.

14 Harding KG, Mudge M, Leinster SJ, et al: Late development of incisional hernias: An unrecognised problem. Br Med J 1983;286:519-520.

15 Anderson G, Boldiston C, Woods S, et al: A cost-effectiveness evaluation of three antimicrobial regimens for the prevention of infective complications after abdominal surgery. Arch Surg 1996;131:744-748.

16 Cruse PJE, Foord R: The epidemiology of wound infection: A 10-year prospective study of 62,939 wounds. Surg Clin North Am 1980; 60:27-40

17 Jarvis W: Selected aspects of the socioeconomic impact of nosocomial infections: Morbidity, mortality, cost and prevention. Infect Control Hosp Epidemiol 1996; 17:552-557.

18 Cahalane MJ, Shapiro ME, Silen W: Abdominal incision: Decision or indecision? Lancet 1989;i:146-148.

19 Bucknall TE, Cox PJ, Ellis H: Burst abdominal and incisional hernia: A prospective study of 1,129 major laparotomies. Br Med J 1982;284: 931-933.
20 Akman PC: A study of 500 incisional hernias. J Int Coll Surg 1962;37:125-142.

21 van der Linden FTPM, van Vroonhoven TJMV: Long-term results after surgical correction of incisional hernia. Neth J Surg 1988;40: 127-129.

22 Riou JPA, Cohen JR, Johnson H: Factors influencing wound dehiscence. Am J Surg 1992; 163:324-330.

23 Greenberg AG, Saik RP, Peskin GW: Wound dehiscence: Pathophysiology and prevention. Arch Surg 1979;114:143-146.

24 Hugh TB: Abdominal wound dehiscence. Aust NZ J Surg 1990;60:153-155.

25 Niggebrügge AHP, Trimbos JB, Hermans J, et al: Influence of abdominal-wound closure technique on complications after surgery: A randomized study. Lancet 1999;353:1563-1567.

26 Bajardi J, Ricevuto C, Mastrandrea G, et al: Il laparocele: Complicanza tardiva della chirurgia bariatrica. Minerva Chir 1993;48:337340 .

27 Thompson WR, Amaral JF, Caldwell MD, et al: Complications and weight loss in 150 consecutive gastric exclusion patients. Am J Surg 1983; 116:602-612.

28 Yale CE: Gastric surgery for morbid obesity: Complications and long-term weight control. Arch Surg 1989;124:941-946.

29 Pories WJ, MacDonald KG Jr, Flickinger EG, et al: Is type II diabetes mellitus (NIDDM) a surgical disease? Am Surg 1992;215:633-643.

30 Brolin RE, Gorman RC, Kenler HK, et al: The dilemma of outcome assessment after operations for morbid obesity. Surgery 1989;105: 337-346.

31 Keill RH, Keitzer WF, Nichols WK, et al: Abdominal wound dehiscence. Arch Surg 1973; 106:573-577.

32 Sugerman HJ, Kellum JM, Reines HD, et al: Greater risk of incisional hernia with morbidly obese than steroid-dependent patients and low recurrence with prefascial polypropylene mesh. Am J Surg 1996;171:80-84

33 Houck JP, Rypins EB, Sarhef IJ, et al: Repair of incisional hernia. Surg Gynecol Obstet 1989; 169:397-399.

34 Wasiljew BK, Winchester DP: Experience with continuous absorbable suture in the closure of abdominal incisions. Surg Gynecol Obstet 1982; 154:378-380.

35 McGinn FP: Effects of hemorrhage on wound healing in the rat. Br J Surg 1976;63:163-168.

36 Niggebrügge AHP, Hansen BE, Trimbos JB, et al: Mechanical factors that influence the incidence of burst abdomen. Eur J Surg 1995;161: 655-661.

37 Daly JW: Dehiscence, evisceration and other complications. Clin Obstet Gynecol 1988;31: 754-760.

38 Armstrong CP, Dixon JM, Duffy SW, et al: Wound healing in obstructive jaundice. $\mathrm{Br} \mathrm{J}$ Surg 1984;71:267-270

39 Bayer I, Ellis H: Jaundice and wound healing: An experimental study. Br J Surg 1976;63:392396.
40 Klinge U, Zheng H, Si Z, et al: Expression of the extracellular matrix proteins collagen I, collagen III and fibronectin and matrix metalloproteinase- 1 and -13 in the skin of patients with inguinal hernia. Eur Surg Res 1999;31:480 490.

41 Friedman DW, Boyd CD, Norton P, et al: Increases in type III collagen gene expression and protein synthesis in patients with inguinal hernias. Ann Surg 1993;218:754-760.

42 Wagh PV, Leverich AP, Sun CN, et al: Direct inguinal herniation in men: A disease of collagen. J Surg Res 1974; 17:425-433.

43 Read RC: A review: The role of protease-antiprotease imbalance in the pathogenesis of herniation and abdominal aortic aneurysm in certain smokers. Postgrad Gen Surg 1992;14:161165.

44 Bellon JM, Bajo A, Honduvilla NG, et al: Fibroblasts from the transversalis fascia of young patients with direct inguinal hernias show constitutive MMP-2 overexpression. Ann Surg 2001;233:287-291.

45 Jackson SR, Avry NC, Tarlton JF, et al: Changes in metabolism of collagen in genitourinary prolapse. Lancet 1996;347:16581661

46 Tamarina NA, McMillan WD, Shively VP, et al: Expression of matrix metalloproteinases and their inhibitors in aneurysms and normal aorta. Surgery 1997;122:264-272.

47 Lehnert B, Wadouth F: High coincidence of inguinal hernias and abdominal aortic aneurysms. Ann Vasc Surg 1992;6:134-137.

48 Pleumeekers HJCM, De Gruijl A, Horman A et al: Prevalence of aortic aneurysm in men with a history of inguinal hernia repair. $\mathrm{Br} \mathrm{J}$ Surg 1999;86:1155-1158.

49 Gilbert JM, Ellis H, Foweraker S: Peritoneal closure after lateral paramedian incision. $\mathrm{Br} J$ Surg 1987;74:113-115.

50 Tera H, Aberg C: Tissue strength of structures involved in musculo-aponeurotic layer sutures in laparotomy incisions. Acta Chir Scand 1976; 142:349-355.

51 Ellis $\mathrm{H}$ : Midline abdominal incisions. $\mathrm{Br} \mathrm{J} \mathrm{Ob-}$ stet Gynaecol 1984;91:1-2.

52 Bucknall TE: Factors influencing wound complications: A clinical and experimental study. Ann R Coll Surg Engl 1983;65:71-77.

53 Brennan TG, Jones NAG, Guillou PJ: Lateral paramedian incision. Br J Surg 1987;74:736737.

54 Greenall MJ, Evans M, Pollock AV: Midline or transverse laparotomy? A random controlled clinical trial. I. Influence on healing. Br J Surg 1980;67:188-190.

55 Greenall MJ, Evans M, Pollock AV: Midline or transverse laparotomy? A random controlled clinical trial. II. Influence of postoperative pulmonary complications. Br J Surg 1980;67:191194.

56 Ellis H, Coleridge-Smith PD, Joyce AD: Abdominal incisions - vertical or transverse? Postgrad Med J 1984;60:407-410.

Yahchouchy-Chouillard/Aura/Picone/ Etienne/Fingerhut 
57 Carrel A: Effet d'un abcès à distance sur la cicatrisation d'une plaie aseptique. C R Soc Biol 1924;90:333-335

58 de Haan BB, Ellis H, Wilks M: The role of infection in wound healing. Surg Gynecol Obstet 1974;138:693-700.

59 Ahrendt GM, Tantry US, Barbul A: Intraabdominal sepsis impairs colonic reparative collagen synthesis. Am J Surg 1996;171:102-108.

60 Soballe PW, Nimbkar NV, Hayward I, et al: Electric cautery lowers the contamination threshold for infection of laparotomies. Am J Surg 1998;175:263-266

61 Franchi M, Ghezzi F, Benedetti-Panici PL, et al: A multicentre collaborative study on the use of cold scalpel and electrocautery for midline abdominal incision. Am J Surg 2001;181:128 132.

62 Moynihan BGA: The ritual of a surgical operation. Br J Surg 1920;8:27-35.

63 Douglas DM: The healing of aponeurotic incisions. Br J Surg 1952;40:79-84.

64 Jenkins TPN: The burst abdominal wound: A mechanical approach. Br J Surg 1976;63:873876.

65 Chu CC, Williams DF: Effects of physical configuration and chemical structure of suture materials on bacterial adhesion. Am J Surg 1984 147:197-204.
66 Hugh TB, Nankivell C, Meagher AP, et al: Is closure of the peritoneal layer necessary in the repair of midline surgical abdominal wounds? World J Surg 1990;14:231-234.

67 Fagniez PL, Hay JM, Lacaine M, Thomsen C: Abdominal midline incision closure. Arch Surg 1985;120:1351-1353.

68 McNeill PM, Sugarman HJ: Continuous absorbable vs. interrupted nonabsorbable fascial closure. Arch Surg 1986;121:821-823.

69 Trimbos JB, Brit Smit I, Holm JP, et al: A randomized clinical trial comparing two methods of fascia closure following midline laparotomy. Arch Surg 1992;127:1232-1234.

70 Brolin RE: Prospective randomized evaluation of fascial closure in gastric bariatric operations. Am J Surg 1996;172:328-331.

71 Cheatham ML, Chapman WC, Key SP, et al: A meta-analysis of selective versus routine nasogastric decompression after elective laparotomy. Ann Surg 1995;221:469-478.

72 Niggebrügge AHP, Trimbos JB, Hermans J, et al: Continuous double loop closure: A new technique for repair of laparotomy wounds. $\mathrm{Br}$ J Surg 1997;84:258-261.

73 Coda A, Bossotti M, Ferri F, et al: Incisional hernia and fascial defect following laparoscopic surgery. Surg Laparosc Endosc Percutan Tech 2000;10:34-38.
74 Montz FG, Holschneider CH, Munro MG: Incisional hernia following laparoscopy: A survey of the American Association of Gynecologic Laparoscopists. Obstet Gynecol 1994;84:881884.

75 Korenkov M, Rixen D, Paul A, et al: Combined abdominal wall paresis and incisional hernia after laparoscopic cholecystectomy. Surg Endosc 1999; 13:268-269.

76 Leibl BJ, Schmedt CG, Schwarz J, et al: Laparoscopic surgery complications associated with trocar tip design: Review of literature and own results. J Laparoendosc Adv Surg Tech A 1999; 9:135-140.

77 Weiland DE, Bay C, Del Sordi S: Choosing the best abdominal closure by meta-analysis. Am J Surg 1998;176:666-670.

78 Hodgson NC, Malthaner RA, Ostbye T: The search for an ideal method of abdominal fascial closure: A meta-analysis. Ann Surg 2000;231: 436-442.

79 Jadad AR, Moore RA, Carroll D, et al: Assessing the quality of reports of randomized clinical trials: Is blinding necessary? Control Clin Trials 1996;17:1-12.

80 Pans A, Desaive C: Use of an absorbable polyglactin mesh for the prevention of incisional hernias. Acta Chir Belg 1995;95:265-268. 